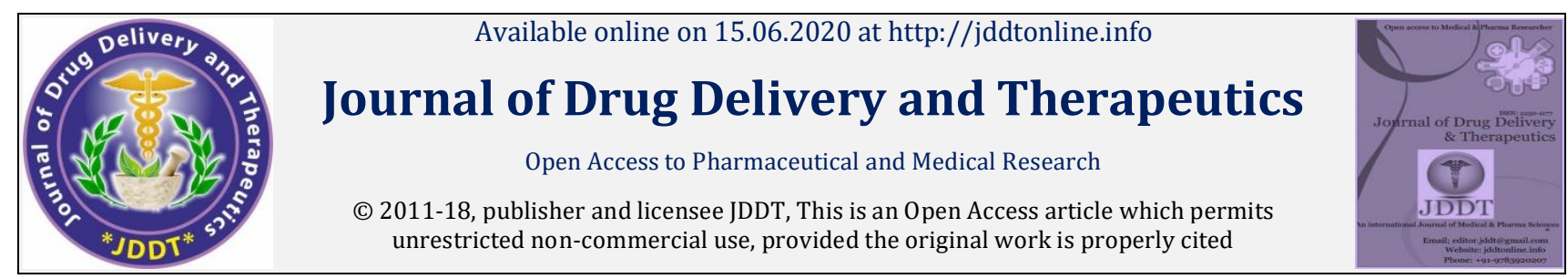

Open $\odot$ Access

Research Article

\title{
A Study on Prescription Pattern of Multivitamins in Type-2 Diabetes Mellitus in Tertiary Care Hospital
}

\author{
Anila A.B. ${ }^{*}$, Ancy P. Shaji1, Sreelekshmi B.S. 1, Mahesh N.M. 1, Vishwanath B A² \\ 1 Department of Pharmacy Practice, Aditya Bangalore Institute of Pharmacy Education and Research Bangalore-560064, Karnataka, India \\ 2 Chairman of Aditya Group of Institution, Bengaluru, India
}

\begin{abstract}
Aim of the study: To study the prescribing pattern of multivitamins in type-2 DM in tertiary care hospitals.

Materials and methods: Human ethical approval was taken from human ethical committee, ABIPER Bangalore. The diabetic patients who satisfied the study criteria were enrolled. The patients data's were collected in specially designed documentation form. The collected data's were assessed using descriptive statistics.

Results: The study was conducted in 158 patients in which most prescriptions [72.17\%] contains water soluble vitamins+minerals. Multivitamins with or without minerals were prescribed for 90[79.76\%] and 30[20.24\%] days respectively. Multivitamins [100\%] were given orally once a day. For indication fatigue [29.11\%], water soluble vitamins+minerals were prescribed mostly. Many DM-2 patients were prescribed with water soluble vitamins+minerals which contain vitaminC and calcium carbonate as main constituents. Some of multivitamins doses were showing compliance as per FDA dose recommendations. Tablet formulation containing fat soluble vitamins+minerals[25.31\%] were prescribed mostly.
\end{abstract}

Conclusions: Mostly water soluble vitamins+minerals were prescribed for DM-2 patients. Multivitamins with or without minerals were prescribed for 90and30 days respectively. All multivitamins were prescribed in oral route. Mostly water soluble vitamins+minerals were prescribed for fatigue illness associated with DM-2 in which vitamin $C$ and calcium carbonate were the main constituents. Some of the prescribed multivitamin doses were within the FDA recommended dose range. Tablet formulations were frequently prescribed with oral antidiabetic drugs.

Keywords: Multivitamins, Diabetes mellitus, Hypertension, Prescription.

Article Info: Received 24 March 2020; Review Completed 20 May 2020; Accepted 27 May 2020; Available online 15 June 2020

Cite this article as:

Anila AB, Ancy PS, Sreelekshmi BS, Mahesh NM, Vishwanath BA, A Study on Prescription Pattern of Multivitamins in Type2 Diabetes Mellitus in Tertiary Care Hospital, Journal of Drug Delivery and Therapeutics. 2020; 10(3-s):91-97 http://dx.doi.org/10.22270/jddt.v10i3-s.4157

$\square$ *Address for Correspondence:

Anila A.B., Department of Pharmacy Practice, Aditya Bangalore Institute of Pharmacy Education and Research Bangalore-560064, Karnataka, India

\section{INTRODUCTION}

Diabetes mellitus is a chronic disease caused by inherited and/or acquired deficiency in production of insulin by the pancreas, or by the ineffectiveness of the insulin produced.Type-2 diabetes mellitus [DM-2], which results either from the inability of the body to respond properly to the action of insulin produced by the pancreas or insufficient amount of insulin is produced 1 .

Multivitamin is a preparation intended to serve as dietary supplements with vitamins, dietary minerals and other nutritional elements, which having the advantages of increasing energy, improving mental concentration, to prevent nutritional deficiencies and they are incredibly easy to use $^{2}$.DM-2 is a multifactorial disease that is typically linked to energy metabolism, particularly carbohydrate and fat management in the organism, however, most micronutrients are also involved in some way either as part of the cause or effect of chronic pathology. The consequences and complications of diabetes are the result of an imbalance between free radical formation and their control by natural antioxidants. Thus, those micronutrients that have an antioxidant function are very important in the prevention of the disease and its complications while other nonantioxidant vitamins have also shown a relationship. To resolve this problem we have to administer multivitamin formulations containing antioxidant and non-antioxidant vitamins $^{3}$ 
Previous studies have recommended that the multivitamins are required to be administered in their therapeutic doses while prescribing for type- 2 diabetic patients. And it is further recommended that the multivitamins along with essential minerals[micronutrients]are to be consumed as a part of the routine diet in diabetic patients ${ }^{4}$.There is no specific guidelines in the treatment of type-2 DM as leafy vegetables and fruits including exercise are commonly recommended along with the diet ${ }^{5}$.

These facts indicate that there is a need to assess the prescribing pattern of multivitamins as alone and in combination with other micronutrients in patients with DM2 .

\section{MATERIALS AND METHODS}

\section{Duration of Study}

$>$ The study conducted for a period of six months

\section{Site of Study}

> Study conducted at tertiary care hospitals[General Hospital, Yelahanka and Aster CMI Hospital, Hebbal]

\section{Study Design}

$>$ A prospective observational study.

\section{Sources of Data and Materials:}

$>$ Patient case sheet

$>$ Medication/treatment chart

$>$ Suitable design documentation form

$>$ Laboratory data report

\section{Study Criteria:}

\section{Inclusion Criteria:}

- $\quad$ Patients who were diagnosed as suffered from type-2 diabetes mellitus as per ICD 10 criteria.

- Patients who were suffered from type-2 diabetes mellitus with or without hypertension.

- $\quad$ Patients of either gender or aged between 30 and 70 years.

\section{Exclusion Criteria:}

- Patients who were suffered from type-1 diabetes mellitus.

- Patients who were suffered from type-2 diabetes mellitus with other co-morbidities other than hypertension.

- $\quad$ Patients who were of either gender and aged up to 29 years and above 70 years.

Method of Data Collection:
- Specifically prepared data collection form

\section{Procedure:}

- The protocol was submitted to Institutional Human Ethical Committee, ABIPER, Bangalore for human ethical approval.

- Those patients who were satisfied the study criteria were enrolled into the study and patient informed consent was obtained.

- The patient's demographic, clinical and medication data were collected into specifically designed data collection form.

- $\quad$ All the data was reviewed from the angle of prescribing pattern of multivitamins, indications, therapeutic regimen with the help of standard references such as WHO guidelines, Micromedex and physician desk reference.

\section{Analysis of Data:}

The collected data was assessed by descriptive statistics.

\section{Human Ethical Clearance Committee Approval:}

$>$ Human ethical clearance committee of ABIPER, Bangalore approved the study and issued a letter of permission to conduct the study.

\section{RESULTS}

- Demographic details of the study patients:

Among the total number of study patients enrolled[158],most of them were male patients[59.50\%].Among various age groups, most of the patients suffering from DM-2 from the age group of 60 70years[37.97\%].Few male patients were smokers[3.17\%] and alcoholic [3.97\%] among the enrolled patients. Among the patients enrolled,36[22.78\%] patients were suffering from DM-2 alone while 122[77.21\%] patients were suffering from DM-2 with hypertension as both are commonly occurring comorbidities.

\section{- Prescription pattern of multivitamins in DM-2 patients:}

The multivitamins were found prescribed alone or in combination with micronutrients such as minerals and antioxidants in all the prescriptions. Of these prescriptions, majority[72.17\%] contained multivitamins+minerals followed by multivitamins+antioxidants [12.65\%], multivitamins with all micronutrients[7.59\%] and only multivitamins[7.59\%].Among the majority of prescriptions, most of the prescriptions[45.56\%] contained water soluble vitamins+minerals followed by fat soluble vitamins+minerals[25.31\%].This data indicates that $3 / 4^{\text {th }}$ of the total prescriptions contain multivitamins with minerals while $1 / 4^{\text {th }}$ of the prescriptions contain multivitamins alone and in combination with antioxidants. 
Table 1: Prescription Pattern of Multivitamins With or Without Micronutrients in DM-2 Patients

\begin{tabular}{|c|c|c|c|}
\hline Sl.No. & Multivitamins & Number of cases[N=158] & Percentage \\
\hline 1. & Water soluble vitamins & 12 & $07.59 \%$ \\
\hline 2. & Fat soluble vitamins & 00 & $00 \%$ \\
\hline \multirow[t]{2}{*}{3.} & Water soluble vitamins+Fat soluble vitamins & 00 & $00 \%$ \\
\hline & Total & 12 & $07.59 \%$ \\
\hline \multicolumn{4}{|c|}{ Multivitamins with minerals } \\
\hline 1. & Water soluble vitamins+Minerals & 72 & $45.56 \%$ \\
\hline 2. & Fat soluble vitamins+Minerals & 40 & $25.31 \%$ \\
\hline \multirow[t]{2}{*}{3.} & $\begin{array}{l}\text { Water soluble vitamins+Fat soluble } \\
\text { vitamins+Minerals }\end{array}$ & 02 & $01.30 \%$ \\
\hline & Total & 114 & $72.17 \%$ \\
\hline \multicolumn{4}{|c|}{ Multivitamins with antioxidants } \\
\hline 1. & Water soluble vitamins+Antioxidants & 14 & $08.86 \%$ \\
\hline 2. & Fat soluble vitamins+Antioxidants & 06 & $03.79 \%$ \\
\hline \multirow[t]{2}{*}{3.} & $\begin{array}{l}\text { Water soluble vitamins+Fat soluble vitamins } \\
+ \text { Antioxidants }\end{array}$ & 00 & $00 \%$ \\
\hline & Total & 20 & $12.65 \%$ \\
\hline \multicolumn{4}{|c|}{ Multivitamins with all micronutrients } \\
\hline \multirow[t]{2}{*}{1.} & $\begin{array}{l}\text { Water soluble vitamins+Fat soluble vitamins } \\
+ \text { Antioxidants+Minerals }\end{array}$ & 12 & $07.59 \%$ \\
\hline & Total & 12 & $07.59 \%$ \\
\hline
\end{tabular}

Notes: 1.DM-2:-Type-2 Diabetes Mellitus. 2. N:-Total number of patients enrolled in study. 3. \%:-Percentage.

\section{- Therapeutic regimen of multivitamins:}

In this study all prescribed multivitamins [100\%] were given once daily. Multivitamins were not prescribed for 15 days and 60 days in any of the prescription. Water soluble vitamins, water soluble vitamin+antioxidant and fat soluble vitamin+antioxidant were prescribed for 30 days[20.24\%]. All multivitamins which were used along with minerals are prescribed for 90 days[79.76\%].All the multivitamins prescribed were administered per oral[100\%].

Table 2: Therapeutic Regimen of Multivitamins [N=158].

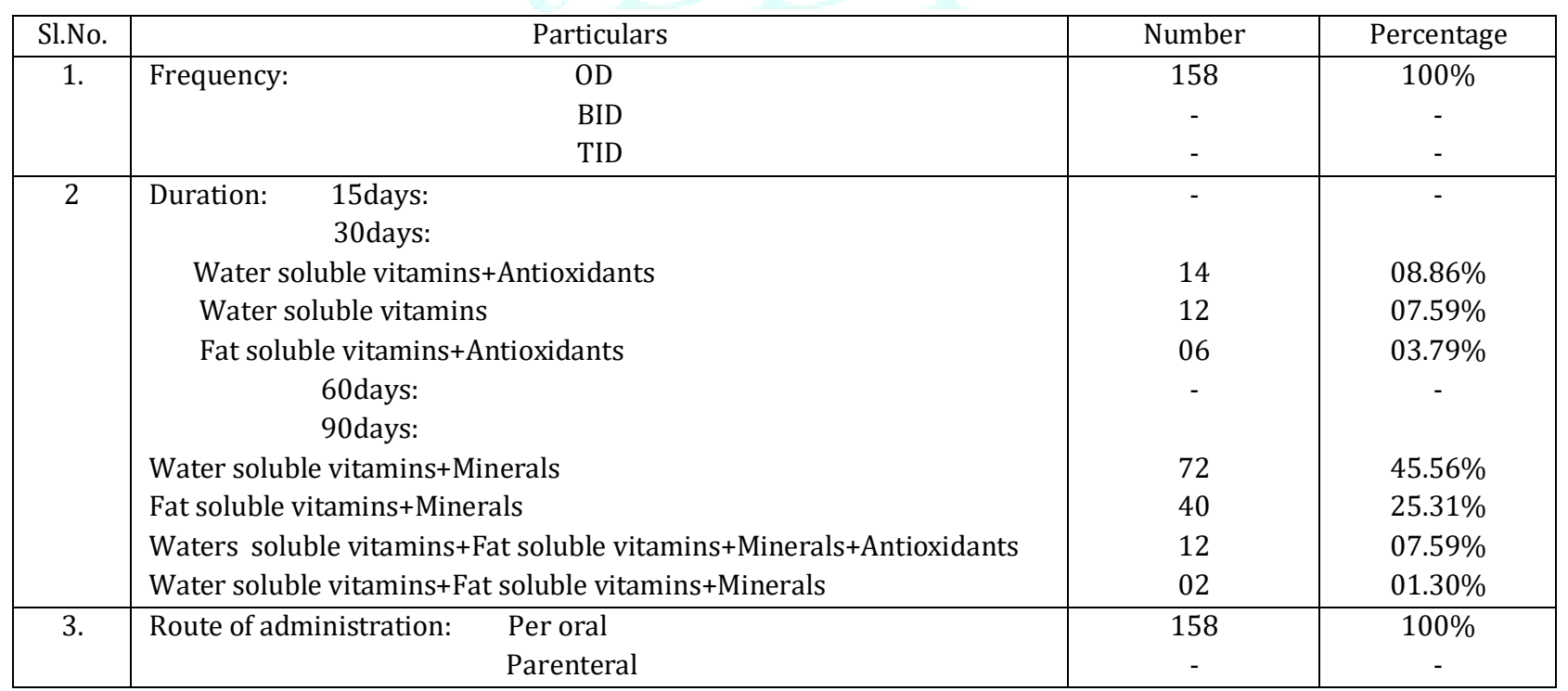

Notes: $1 . N$ :-Total number of patients enrolled in study $\quad$ 2. OD:-Once daily. $\quad$ 3. BID:-Twice daily

4. TID:-Thrice daily. 


\section{- Indications for which multivitamins are prescribed among DM-2 patients:}

The chief indications for which multivitamins prescribed among DM-2 patients were found to be dizziness, fatigue and lethargy. Of these multivitamins, majority of prescriptions [72.17\%] contained water soluble vitamins+minerals followed by multivitamins+antioxidants [12.65\%], multivitamins with all micronutrients[7.59\%] and only multivitamins[7.59\%] for the above mentioned indications. Among the majority of prescriptions that contained multivitamins and minerals, most of the prescription [45.56\%] contained water soluble vitamins+ minerals succeeded by fat soluble vitamins+ minerals [25.31\%].For the indication fatigue[29.11\%],water soluble vitamins+ minerals were prescribed mostly followed by lethargy [12.02\%] and dizziness[04.43\%].

\section{- Composition of multivitamins:}

Among water soluble vitamins chromium polynicotinate [200mcg] was present. Chromium polynicotinate was reported for increase insulin sensitivity. Among water soluble vitamins+minerals, vitamin C[150mg] and calcium[20mg] were added in more quantity among others. Among formulation containing water soluble vitamins+fat soluble vitamins + minerals+ antioxidants, methylcobalamine [1500mcg], alfa-tocoferol [200mg], magnesium oxide [66.32mg] and alfa-lipoic acid[200mg] were more in quantity. Among formulations containing water soluble vitamins+fat soluble vitamins+minerals, vitamin $\mathrm{B} 5[100 \mathrm{mg}]$, vitamin E[15mg] and elemental zinc[22mg] was added in more quantity. Among formulation containing fat soluble vitamins and minerals, vitamin $\mathrm{D}$ [250IU] and calcium carbonate[500mg] were added in more quantity. No study results are available to comparing with our study.

Table 3: Compositions of Multivitamins

\begin{tabular}{|c|c|c|}
\hline Sl.No. & Particulars & Composition[mg:-milligram, mcg:-microgram, IU:-international unit] \\
\hline 1. & $\begin{array}{l}\text { Water soluble vitamin Fat soluble } \\
\text { vitamins+Minerals+Antioxidants. }\end{array}$ & $\begin{array}{l}\text { Alpha lipoic acid200mg; Beta carotene3mg; Methylcobalamine1500mcg; } \\
\text { Zinc oxide } 24.89 \mathrm{mg} \text {; Selenious acid0.114mg; Chromium chloride0.152mg; } \\
\text { Light magnesium oxide 66.32mg; Magnesium sulphate6.152mg; Alfa- } \\
\text { tocoferol200mg. }\end{array}$ \\
\hline 2. & Fat soluble vitamins+Minerals. & Vitamin D250IU; Calcium carbonate 500mg. \\
\hline 3. & Water soluble vitamins+Minerals. & 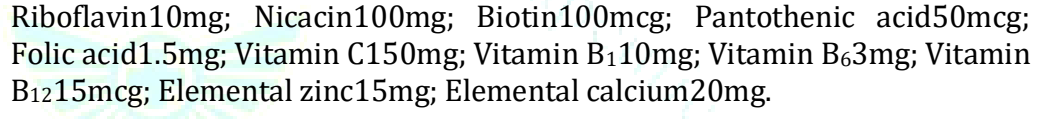 \\
\hline 4. & Water soluble vitamins+Antioxidants. & Vitamin C300mg; Beta carotene3mg. \\
\hline 5. & Water soluble vitamins. & $\begin{array}{l}\text { Vitamin C152mg; Folic acid1.5mg; Methylcobalamine1500mcg; } \\
\text { Inositol100mg; Chromium polynicotinate200mcg; Benfotiamine150mg. }\end{array}$ \\
\hline 6. & Fat soluble vitamins + Antioxidants. & Tocoferol acetate $400 \mathrm{mg}$ \\
\hline 7. & $\begin{array}{l}\text { Water soluble vitamins+Fat soluble } \\
\text { vitamins+Minerals. }\end{array}$ & $\begin{array}{l}\text { Vitamin C75mg, Vitamin } \mathrm{B}_{3} 50 \mathrm{mg} ; \text { Vitamin } \mathrm{B}_{1} 10 \mathrm{mg} ; \text { Vitamin } \mathrm{B}_{2} 10 \mathrm{mg} ; \\
\text { Vitamin } \mathrm{B}_{5} 100 \mathrm{mg} ; \text { Vitamin } \mathrm{B}_{6} 2 \mathrm{mg} ; \text { Vitamin } \mathrm{B}_{12} 7.5 \mathrm{mcg} \text {; Vitamin } \mathrm{D}_{3} 400 \mathrm{IU} ; \\
\text { Vitamin } \mathrm{D}_{4} 5000 \mathrm{IU} \text {; Vitamin E15mg; Folic acid1mg; Biotin150mcg; Elemental } \\
\text { magnesium18mg; Elemental manganese0.9mg; Elemental copper0.5mg; } \\
\text { Elemental zinc22mg; Elemental iron150mcg; Elemental selenium50mcg. }\end{array}$ \\
\hline
\end{tabular}


- Prescribing pattern of therapeutic dosage of multivitamin formulations:

Vitamin B12, Vitamin B6, Vitamin B9, Vitamin D, Vitamin E, magnesium sulphate, calcium carbonate and elemental zinc were in compliance with FDA recommended dose. Vitamin
B2, Vitamin B3, Vitamin B7,Vitamin B5, Vitamin B1, alphatocoferol, zinc oxide, selenium acid, chromic chloride, light magnesium oxide, alpha-lipoic acid and beta carotene, elemental-calcium, magnesium, manganese, copper, iron, selenium were in noncompliance with FDA recommended dose.

Table 4: Prescribing Pattern of Therapeutic Dosage of Multivitamin Formulations

\begin{tabular}{|c|c|c|c|c|}
\hline Sl.No. & Multivitamins & $\begin{array}{l}\text { Dose per day[mg: milligram, } \\
\text { mcg:-microgram, IU:- } \\
\text { international unit] }\end{array}$ & $\begin{array}{l}\text { FDA recommended dose[mg:- } \\
\text { milligram, mcg:-mi crogram, IU:- } \\
\text { international unit] }\end{array}$ & C and NC \\
\hline \multirow[t]{10}{*}{1.} & Water soluble vitamins: & \multirow[b]{2}{*}{$7.5 \mathrm{mcg}$} & & \\
\hline & Vitamin $\mathrm{B}_{12}$ & & $6-500 \mathrm{mcg}$ & $\mathrm{C}$ \\
\hline & Vitamin $B_{2}$ & $10 \mathrm{mg}$ & $1.5-3 \mathrm{mg}$ & NC \\
\hline & Vitamin $B_{3}$ & $100 \mathrm{mg}, 50 \mathrm{mg}$ & $14-35 \mathrm{mg}$ & NC \\
\hline & Vitamin $B_{7}$ & $100 \mathrm{mcg}, 150 \mathrm{mcg}$ & $300-400 \mathrm{mcg}$ & NC \\
\hline & Vitamin $B_{5}$ & $150 \mathrm{mcg}, 100 \mathrm{mg}$ & $5-20 \mathrm{mg}$ & NC \\
\hline & Vitamin $B_{9}$ & $1 \mathrm{mg}$ & $400-1000 \mathrm{mcg}$ & $\mathrm{C}$ \\
\hline & Vitamin C & $150 \mathrm{mg}, 300 \mathrm{mg}, 152 \mathrm{mg}, 75 \mathrm{mg}$ & $75-2000 \mathrm{mg}$ & $\mathrm{C}$ \\
\hline & Vitamin $B_{1}$ & $10 \mathrm{mg}, 150 \mathrm{mg}$ & $1.5-3 \mathrm{mg}$ & NC \\
\hline & VitaminB $_{6}$ & $3 \mathrm{mg}, 2 \mathrm{mg}$ & $1.3-100 \mathrm{mg}$ & $\mathrm{C}$ \\
\hline \multirow[t]{4}{*}{2.} & Fat soluble vitamins: & & & \multirow[b]{2}{*}{ NC } \\
\hline & Alpha-tocoferol & 200mg & $15-30 \mathrm{mg}$ & \\
\hline & Vitamin D & $400 \mathrm{IU}$ & $600-4000 \mathrm{IU}$ & $\mathrm{C}$ \\
\hline & Vitamin E & $400 \mathrm{mg}, 15 \mathrm{mg}$ & $15-100 \mathrm{mg}$ & $\mathrm{C}$ \\
\hline \multirow[t]{14}{*}{3.} & Minerals: & 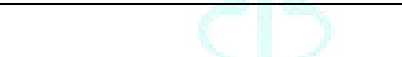 & & \multirow[b]{2}{*}{ NC } \\
\hline & Zinc oxide & $24.89 \mathrm{mg}$ & $50-80 \mathrm{mg}$ & \\
\hline & Selenium acid & $0.114 \mathrm{mg}$ & $15-30 \mathrm{mcg}$ & NC \\
\hline & Chromic chloride & $0.152 \mathrm{mg}$ & $200-1000 \mathrm{mcg}$ & NC \\
\hline & Light magnesium oxide & $66.32 \mathrm{mg}$ & $400-800 \mathrm{mg}$ & NC \\
\hline & Magnesium sulphate & $6.152 \mathrm{mg}$ & $1-40 \mathrm{mg}$ & $\mathrm{C}$ \\
\hline & Calcium carbonate & $500 \mathrm{mg}$ & $500-1000 \mathrm{mg}$ & $\mathrm{C}$ \\
\hline & Elemental zinc & $15 \mathrm{mg}, 22 \mathrm{mg}$ & $8-40 \mathrm{mg}$ & $\mathrm{C}$ \\
\hline & Elemental calcium & $20 \mathrm{mg}$ & $1000-2500 \mathrm{mg}$ & NC \\
\hline & Elemental magnesium & $18 \mathrm{mg}$ & $350-420 \mathrm{mg}$ & NC \\
\hline & Elemental manganese & $0.9 \mathrm{mg}$ & $1.8-11 \mathrm{mg}$ & NC \\
\hline & Elemental copper & $0.5 \mathrm{mg}$ & $900-1000 \mathrm{mcg}$ & NC \\
\hline & Elemental iron & $150 \mathrm{mcg}$ & $8-45 \mathrm{mg}$ & NC \\
\hline & Elemental selenium & $50 \mathrm{mcg}$ & $55-400 \mathrm{mcg}$ & NC \\
\hline 4. & Antioxidants: & & & \\
\hline & Alpha lipoic acid & $200 \mathrm{mg}$ & $600-1800 \mathrm{mg}$ & NC \\
\hline & Beta carotene & $3 \mathrm{mg}$ & $6-15 \mathrm{mg}$ & NC \\
\hline & Vitamin E & $400 \mathrm{mg}$ & 15-1000mg & $\mathrm{C}$ \\
\hline
\end{tabular}




\section{- Formulation of multivitamins:}

Majority of the prescription contain multivitamins were in tablet form[50.64\%] followed by capsules[49.36\%].Among tablet formulation, fat soluble vitamin minerals[25.31\%] were mostly prescribed while in capsule formulation water soluble vitamins+minerals[45.56\%] prescribed.

Table 5: Formulation of Multivitamins

\begin{tabular}{|c|c|c|c|}
\hline Sl.No. & Particulars & Number $[\mathrm{N}=158]$ & Percentage \\
\hline \multirow[t]{7}{*}{1.} & Tablets: & & \\
\hline & Water soluble vitamins & 12 & $07.59 \%$ \\
\hline & Water soluble vitamins+Antioxidants & 14 & $08.86 \%$ \\
\hline & Fat soluble vitamins+Minerals & 40 & $25.31 \%$ \\
\hline & Water soluble vitamins+Fat soluble vitamins+Minerals & 02 & $01.31 \%$ \\
\hline & Water soluble vitamins+Fat soluble vitamins+Minerals+Antioxidants & 12 & $07.59 \%$ \\
\hline & Total & 80 & $50.64 \%$ \\
\hline \multirow[t]{4}{*}{2.} & Capsules: & & \\
\hline & Water soluble vitamins+Minerals & 72 & $45.56 \%$ \\
\hline & Fat soluble vitamins+Antioxidants & 06 & $03.79 \%$ \\
\hline & Total & 78 & $49.36 \%$ \\
\hline
\end{tabular}

Notes: 1.N:-Total number of patients enrolled in study. 2. \%:-Percentage

\section{DISCUSSION}

We had done our project on the prescription pattern of multivitamins in type- 2 diabetic patients because mainly diabetic patients were suffering from nutritional deficiencies. There is a need to study the utilization of micronutrients especially in diabetes mellitus type-2[DM-2] patients.

We had done our study in $173 \mathrm{DM}-2$ patients with or without hypertension from which $15(8.67 \%)$ cases were dropped due to incomplete data. Then we had completed our study in 158 patients in which most of them were male patients (59.50\%-[94]) who were at the age group of 30-70years.Out of 158 patients, $122(77.21 \%$ ) were suffering from DM-2 with hypertension.

- Prescription pattern of multivitamins with or without micronutrients in DM-2 patients:

Among 158 prescriptions, multivitamins+minerals were prescribed in $114(72.17 \%)$ prescriptions followed by multivitamins+antioxidants, multivitamin+micronutrients and multivitamins. Out of these 114 prescriptions, multivitamins+minerals in that water soluble vitamins+minerals were prescribed more $72(45.56 \%)$.There were no previous studies which have assessed such correlation.

\section{- Prescription pattern of anti-diabetic drugs:}

Totally 233 anti-diabetic drugs were prescribed for 158 patients suffering from diabetes mellitus, out of these patients $155(66.52 \%)$ were treated with various oral antidiabetic drugs prescribed alone and in combination. Among oral anti-diabetic drugs, biguanide([42]-18.02\%) was mostly prescribed in which metformin[34.33\%] was prescribed more as alone and in combination with other anti-diabetic drugs. When comparing with previous studies, metformin is less frequently prescribed in our study6,7,8.

\section{- Prescription pattern of multivitamins with DM-2 drugs:}

In our study $40.4 \%$ of multivitamins were prescribed with or without micronutrients along with anti-diabetic drugs in DM-2 patients. This value was found to be $18.48 \%$ more and $6.2 \%$ less when compared to the study conducted by Mayor $S$ et $\mathrm{al}(2006)^{8}$ and Wysowski DK et al $(2015)^{6}$ respectively.Further studies may be needed to compare prescribing pattern of multivitamin separately in outpatients and inpatients set up for DM-2 patients.

\section{- Analysis of therapeutic regimen of multivitamins with diet among DM-2 patients:}

All multivitamins $(100 \%)$ were prescribed once daily for oral administration. Water soluble vitamins, water soluble+antioxidants and fat soluble+antioxidants were prescribed for 30 days(20.24\%) while multivitamins used along with minerals were for 90 days(79.76\%).There were no related studies to compare these results according to our knowledge.

\section{- Analysis of indications for which multivitamins were prescribed among DM-2 patients:}

Multivitamins were prescribed with and without micronutrients to treat dizziness, fatigue and lethargy in DM-2 patients. Our study indicates that the water soluble multivitamins with and without micronutrients were prescribed mostly to treat fatigue and dizziness. However, a study conducted by Martin et al concluded that multivitamins were prescribed as a potential therapy to improve endothelium dysfunction and reduce insulin resistance ${ }^{9}$.These data indicates that the choices of multivitamins are different while treating DM-2 patients. Further studies are required to understand the above topic in more deeply.

\section{- Analyzing the composition of prescribed multivitamin formulations:}

Among water soluble vitamins, chromium polynicotinate (200mcg) composition is more which was reported to increase insulin sensitivity. Quantity of vitamin C $(150 \mathrm{mg})$ and calcium $(20 \mathrm{mg})$ compositions were more in water soluble vitamins+minerals while for fat soluble vitamins+minerals, vitamin $\mathrm{E}(250 \mathrm{IU})$ and calcium (500mg) were more. Among formulation containing water soluble and fat soluble vitamins with minerals and antioxidants containing methylcobalamine $(1500 \mathrm{mcg})$, alfatocoferol(200mg),magnesium oxide(66.32mg) and alfalipoic acid(200mg) in more quantity while water soluble and fat soluble vitamins with minerals containing vitamin B5(100mg),vitamin E(15mg) and elemental zinc(22mg) in more quantity. No relevant study data was available for comparing these results. 
- To assess the therapeutic dosage of various vitamin formulations with or without minerals as per standard references:

Some vitamin formulations were in compliance with FDA recommended dose while some were in non-compliance with FDA recommended dose.

\section{- Assessment of the formulations of multivitamins, which were commonly, prescribed for DM -2 patients:}

In majority of the prescriptions, multivitamins were in tablet form(50.64\%) followed by capsule(49.36\%).Among tablet formulation, fat soluble vitamin+minerals (25.31\%) were mostly prescribed while in capsule formulation water soluble vitamins+minerals $(45.56 \%)$ were more. There was no head to head study for comparing these results.

\section{CONCLUSION}

- Multivitamins were prescribed alone and in combination with micronutrients along anti-diabetic drugs to treat DM-2 patients in which water soluble vitamins were frequently used.

- DM-2 patients were frequently treated with the combination of human insulin and oral anti-diabetic drugs. Among oral drugs metformin was frequently used.

- $\quad$ All DM-2 patients were prescribed with multivitamins as alone or in combination by oral route once daily. Multivitamins without minerals were prescribed for 1 month and with minerals for 3months.

- Multivitamins were prescribed with and without micronutrients to treat dizziness, fatigue and lethargy in DM-2 patients. Our study indicates that the water soluble multivitamins with and without micronutrients were prescribed mostly to treat fatigue and dizziness.

- Many DM-2 patients were prescribed with formulations containing water soluble vitamins+ minerals which contain vitamin $\mathrm{C}$ and calcium carbonate as main constituents. Among water soluble vitamins chromium polynicotinate reported to increase insulin sensitivity.

- Some of the prescribed multivitamins doses were within FDA recommended dose range.

- Most of the multivitamins prescribed frequently as alone or in combination with micronutrients was formulated in tablet form followed by capsule.

\section{ACKNOWLEDGEMENT}

"If any of you lack wisdom, let him ask of GOD, who gives you to all liberally and reproach and it will be given to him."

We are deeply indebted to the Almighty GOD, for enabling us to complete this project work in a fine manner.

We owe a great deal of thanks to many people who supported us with their time and encouragement throughout this enormous project work.
We are very grateful to RGUHS for granting us permission to do this work.

The present study has been undertaken and completed under the expert guidance and encouragement of Dr. Mahesh N.M, M.Pharm., Ph.D. professor and head, Department of Pharmacy Practice, ABIPER, Bangalore.

We are very grateful to our Co-guide Dr. Mahesh D.M., Endocrinologist, ASTER CMI Hospital, Hebbal, Bangalore.

We are very thankful to our visionary Chairman Dr. B.A Viswanathan M.Pharm, Ph.D. for this sincere gratitude and support.

We are very grateful to HOD Dr. Mahesh N.M, M.Pharm., Ph.D. for his unending help and support throughout our project.

We express our deepest sense of gratitude to Principal of ABIPER Dr. Ramkumar, M.Pharm, MBA, Ph.D. for providing the necessary facilities to carry out our thesis work.

Our sincere thanks to Dr. Ritty Sara Cherian, Kalyanam Bharathi and other teachers for providing their support to accomplish this wonderful work.

At this moment we would love to express our thanks to seniors, juniors and non-teaching staffs for supporting us throughout our work in their own way.

We take this opportunity to thank the Librarian for extending library facilities throughout this study.

\section{CONFLICT OF INTEREST}

There was no conflict of interest among the authors.

\section{REFERENCES}

1. Diabetesmellitus [Internet] [2018 Dec 10].Available from: https: www.whoIntmediacentrefact

2. Advantages and disadvantages of multivitamins [Internet] [2018 Dec 12].Available from: https:connectusfund.org7-advantagesand disadvantages-of-multivitamins

3. Endocr Metab Immune Disord Drug Targets. 2015; 15(1):54-63. doi:[10.2174/1871 530314666141111103217$]$

4. Multivitamins with minerals dosage [Internet] [2018 Aug 13]. Available from: https.www.drugs.com/dosage/multivitaminswith minerals.html

5. Centrum otc [Internet] [2018 Dec 12].Available from: https:www.empr.com centrum drug 22

6. Wysowski DK, Mohan Investigation of outpatient prescribing pattern of anti-diabetic drug in type-2 diabetic patients.10.9790/3008-10242630

7. Dr.Muhammad Mahbubul Alam, Dr.Feroza Parveen.Prescribing trends in outpatient department. Bangladesh medical journal; 2011

8. Mayor S.Triplitt CL, Cintrill JA.Prescribing pattern in diabetic outpatient. Pharmacology online; 2007

9. Martin BC, Warram JH, Krolewski AS, Bergman RN etal.Study of the effect of multivitamin on patient with type-2 diabetes 2008; 340(8825):925-9 